Journal of Education and Vocational Research

Vol. 4, No. 1, pp. 18-23, Jan 2013 (ISSN 2221-2590)

\title{
Digital Inequality amongst University Students in the Tshwane Region
}

\author{
Wilfried Ndiaye Kassangoye, *Johan de Jager, Robert Rugimbana \\ Tshwane University of Technology, South Africa \\ *dejagerjw@tut.ac.za
}

\begin{abstract}
Whilst the main objective of this paper is to investigate the digital divide amongst the university students in the Tshwane region of South Africa, the purpose is to determine a generalisable profile that would characterize their Internet usage behaviour. The research design consisted of a descriptive design. The convenience sampling method was applied and the research instrument was a structured questionnaire, which was employed to collect the final data amongst a total of 300 university students (selected from two universities in South Africa, TUT and UP by way of self-administration questionnaires. Male and female students were almost equally distributed. The significance of the results obtained was then tested through analytical tools embedded in the computer software STATA 11. The analytical tools were used to quantitatively analyze the data, out of which different inferences were drawn. The main findings were that the university students in the Tshwane region can be profiled on the basis of the results obtained over and above specific situational and personal characteristics, provides important opportunities for marketers for better understanding the needs and expectations of the university students; and by extension, to those of the youth market, since the sample elements belonged to the 18 to 34 years old age group. A proper segmentation would present an important mean by which marketers can keep in touch with their consumers' expectations.
\end{abstract}

Key words: Internet usage, digital inequality, university students.

\section{Introduction}

Information and communication technologies (ICTs) have impacted the educational sector of the world, though it is accepted that the rate of deployment of new technologies has been lower in developing countries, especially those of sub-Saharan Africa (Idowu, Idowu \& Adagunodo, 2004). The Internet has emerged as arguably the most visible component of the dynamic developments of Information and Communication Technologies (ICTs). The rate of adoption of the Internet exceeds that of all technologies before it. Its uses range from communication and publishing to research. It has impacted, albeit differentially, every sector from manufacturing and services to education. Higher education is particularly crucial to long running economic growth because it is the source of knowledge workers and an important source of inventive outputs. The role of universities as centers of research and diffusion of findings will become increasingly important in the 21st century (Rosenberg, 2001). Higher education institutions produce skilled engineers and scientists whose skills and knowledge drive the industrialization process. Again, as competitiveness becomes less price-based and more innovation-driven, the dual role of universities listed above will become a decisive factor in transforming economies (Idowu, Idowu \& Adagunodo, 2004). Furthermore, Li and Kirkup (2005) explain that as far as the Internet is concerned, students work in local or national contexts and have differences in other aspects of their identities. Such differences are referred to as a "digital inequality" (Di Maggio, Hargittai, Celeste \& Shafer, 2004), which consists of analysing the differences in various dimensions between those who access the Internet. This paper reports a research conducted on university students in the Tshwane region of South Africa, which investigated their attitudes towards using the Internet and their Internet usage patterns, to investigate what differences in Internet usage exist between the two institutions (TUT and UP) in terms of ICT, particularly Internet usage by their respective students. It reports on only one particular aspect of the research: a questionnaire survey carried out with samples of male and female students in the 18 to 34 years age group who have access to the Internet and confirmed using it. 


\section{Background of the Research}

Early studies aiming at investigating the differences in ICT or the specifically Internet (usage, adoption, etc.) in particular setting have recurrently used the term "digital divide". This term originates in the 90 's and was first used in a survey from the National Telecommunication \& Information Administration (NTIA). According to Castaño-Muñoz, the term digital divide refers to an analysis of the dichotomy of groups which did or did not have access to and use of the Internet. With time, however, the concept has evolved from an analysis of the differences in access and effective use from a dichotomous point of view (those who do or do not have access to or use the Internet) to a more complex analysis of the differences in various dimensions between those who access the Internet, resulting in a certain conceptual ambiguity: hence the term digital inequality (Di Maggio et al., 2004). The concept of "digital inequality" takes into account all the dimensions which have become included in the concept of digital divide, and includes a social vision of the technology which goes beyond the differences in the defined dimension. It also takes into account the determinants and the resulting social implications, so allowing exploration of the construction of inequality through the combination of technical and social resources. Such exploration requires explanatory models which would help make the difference between usage patterns and Internet adoption, as well as helping in establishing a direct link between usage behavior and the social and institutional context in which they take place. Previous research have been conducted to determine the extents of inequalities and the digital divide (i.e. Van Dijk \& Hacker, 2000; Hargittai, 2002; Di Maggio et al, 2004; Van Dijk, 2006) and most of them concur in that at least four factors should serve as a basis to do so:

- Access (Internet), which includes the motivational differences for the first move towards ITC (motivational access) but in this case focuses only on the differences in access to technological infrastructure (the classic digital divide);

- Digital literacy, the different skills for Internet use;

- Intensity of use (differences in the time of use);

- Purpose of use of the Internet by individuals (differences in Internet usage).

This model, including the four above factors serves as basis in this paper in order to investigate the digital divide between the students of the two selected institutions in the Tshwane region. For the purpose of clarity in the investigation, the objectives that stemmed from this concept is to provide an overview of the current state of the four factors (access, digital literacy, intensity of use, purpose of use) and see if differences exist between the students of TUT and UP in terms of Internet usage. Although this paper solely provides an exhaustive theoretical overview of the digital inequalities between the university students in the Tshwane region, comparing these results with that of other studies conducted abroad may be fruitful in that other similarities/differences could be discovered and other investigative factors may emerge.

Rationale: Whilst the main objective of this paper is to investigate the digital divide amongst the university students in the Tshwane region, the purpose is to determine a generalisable profile that would characterize their Internet usage behaviour.

\section{Methodology}

The approach consisted of a descriptive design in order to provide a clear profile of Internet usage patterns amongst university students in the Tshwane region. The convenience sampling method was applied and the research instrument was a structured questionnaire, which was employed to collect the final data amongst a total of 300 university students (selected from TUT and UP), by way of self-administration. Male and female students were almost equally distributed. The significance of the results obtained was then tested through analytical tools embedded in the computer software STATA 11. The analytical tools were used to quantitatively analyze the data, out of which we drew different inferences made in this paper.

Data Management and Statistical Data Analysis: Data was captured in Excel and converted to STATA 11 in which analysis was performed, by Stat/Transfer. The comparisons between categorical variables were performed by using chi-square tests. The Analysis was performed at 95\% confidence limit. Summary statistics are supplied as proportions and frequency counts. 


\section{Results and Discussion}

In this section the results are presented and discussed. The results are presented by means of simple descriptive statistics.

\section{Figure 1: Gender distribution of the sample}

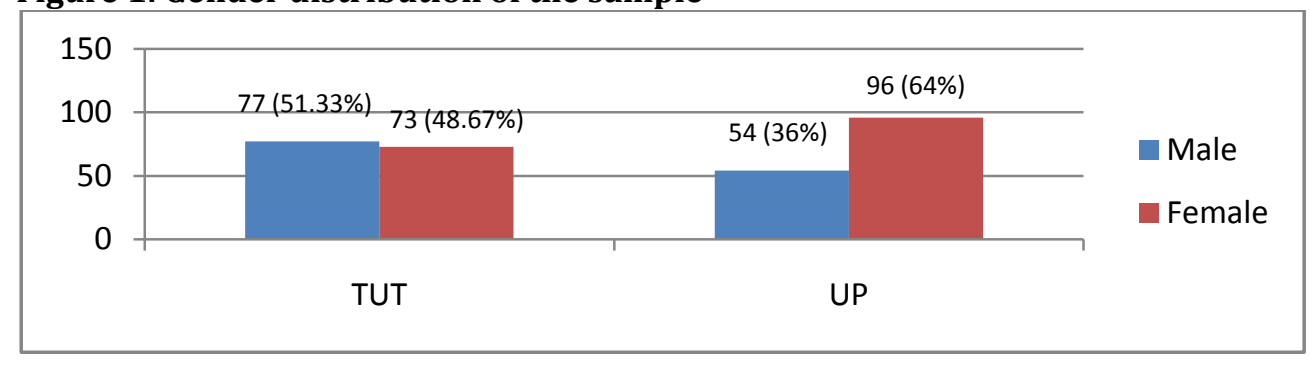

Figure 1 illustrates the gender distribution of the university students in the Tshwane region. Overall the sample was composed of 133 (44.33\%) male and 167 (55.67\%) female. In TUT, the genders were almost equally distributed: 77 (51.33\%) were male and 73 (48.67\%) were female. Whereas in UP, the genders were imbalanced amongst the respondents: 54 (36\%) were male and 96 (64\%) were female. The following paragraphs present the results of each factor (access, digital literacy, intensity of use, purpose of use) corresponding to the model on which the current study was based. Furthermore, for each attribute, the significance of the chi-square test at a 95\% confidence level (Chi-square should be lesser than 0.05) confirms that differences exist between TUT and UP with regard to that particular factor.

Figure 2: Internet access

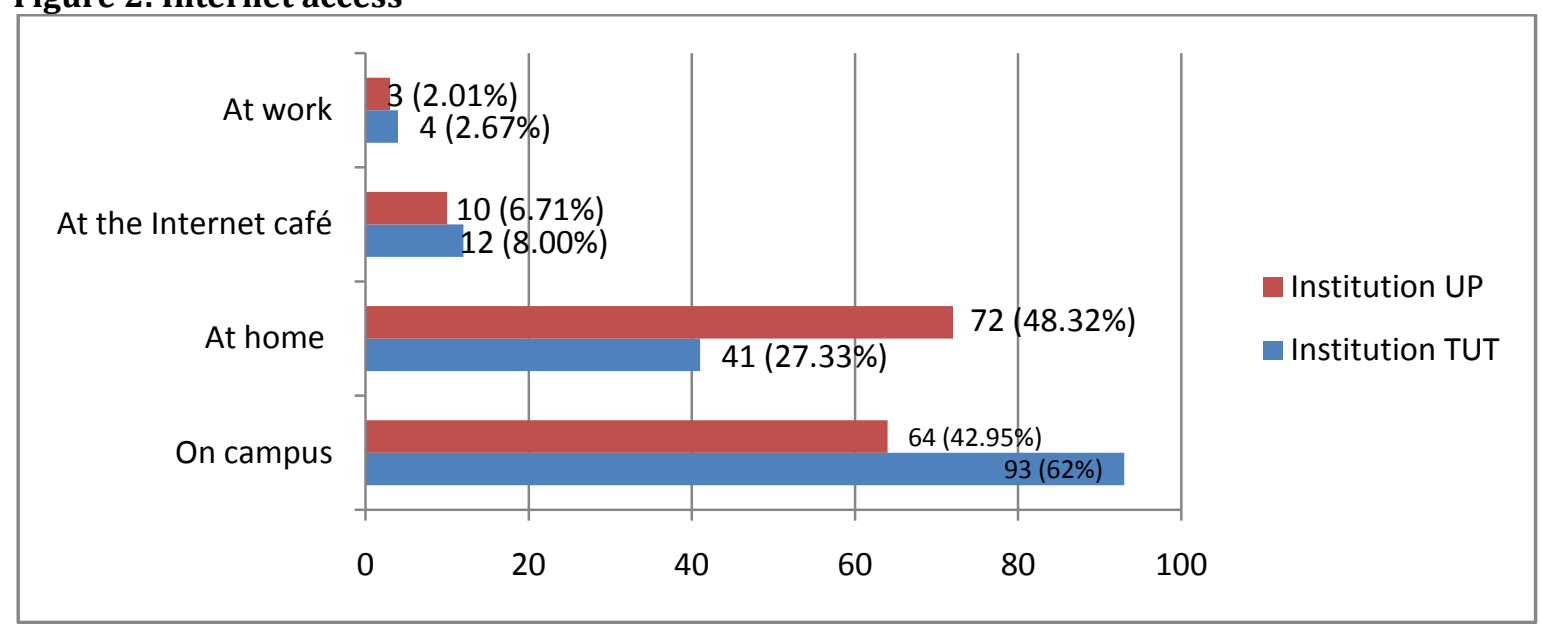

Pearson $\mathrm{chi}=14.1826 \operatorname{Pr}=0.003$

Figure 2 presents the university students' favorite place for accessing the Internet, based on the facilities that they have at their disposal. Two main places of access emerge from the result of figure II: Amongst the students of UP, $72(48.32 \%)$ mostly access the Internet at home and $64(42.95 \%)$ on campus. As for the TUT students, 93 (62\%) mostly access it on campus and $41(27.33 \%)$ access it at home. At the 5\% level of significance, there is a statistically significant association between the favourite places of access of UP and TUT students respectively: which implies that there indeed are differences in accessing the Internet between the UP students and those of TUT. Figure III presents the university students' self-assessment of their level of digital literacy. Overall, most of the sample believes that they have a moderate level of digital literacy. Amongst them, 85 (45.70\%) were UP students and 101 (54.30\%) were TUT students. At the 5\% level of significance, there is a statistically significant association between the digital literacy of UP and TUT students respectively: which implies that there indeed are differences in digital literacy (or in the skills required to use the Internet) between the UP students and those of TUT. 
Figure 3: Digital literacy

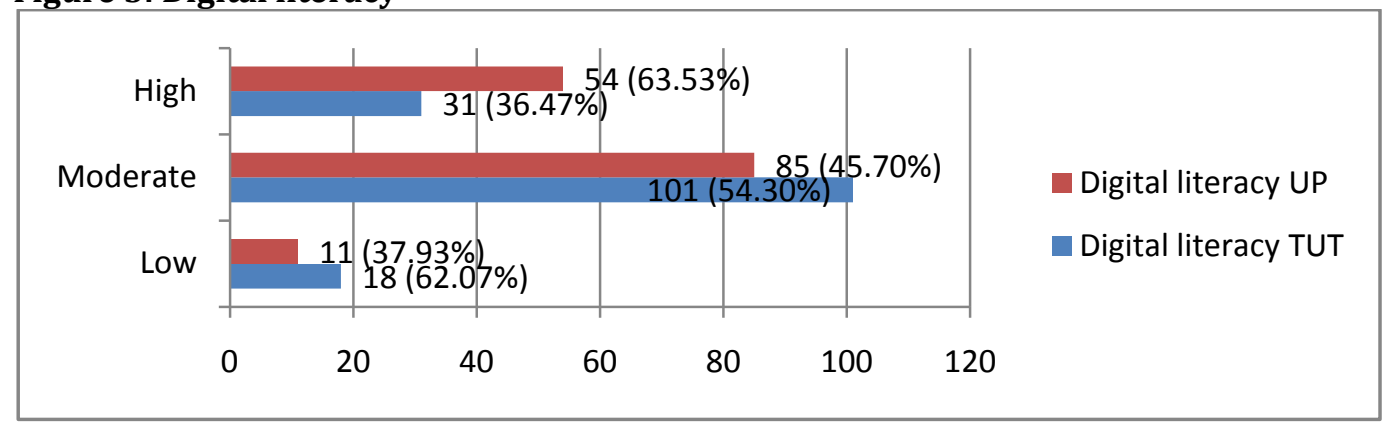

Pearson chi $=9.2895 \operatorname{Pr}=0.010$

Figure 4 presents the university students' Internet usage intensity. Two main places of access emerge from the result of figure IV: (1) amongst the students who use the Internet between 0 and 29 minutes, 62 (63.27\%) are UP students and 36 (36.73\%) are TUT students. As for those who use it (2) between 30 and 59 minutes, $62(50.82 \%)$ are TUT students and $60(49.18 \%)$ are UP students. At the $5 \%$ level of significance, there is a statistically significant association between the Internet usage intensity of UP and TUT students respectively: which implies that there indeed are differences in the times of use between the UP students and those of TUT.

Figure 4: Intensity of use

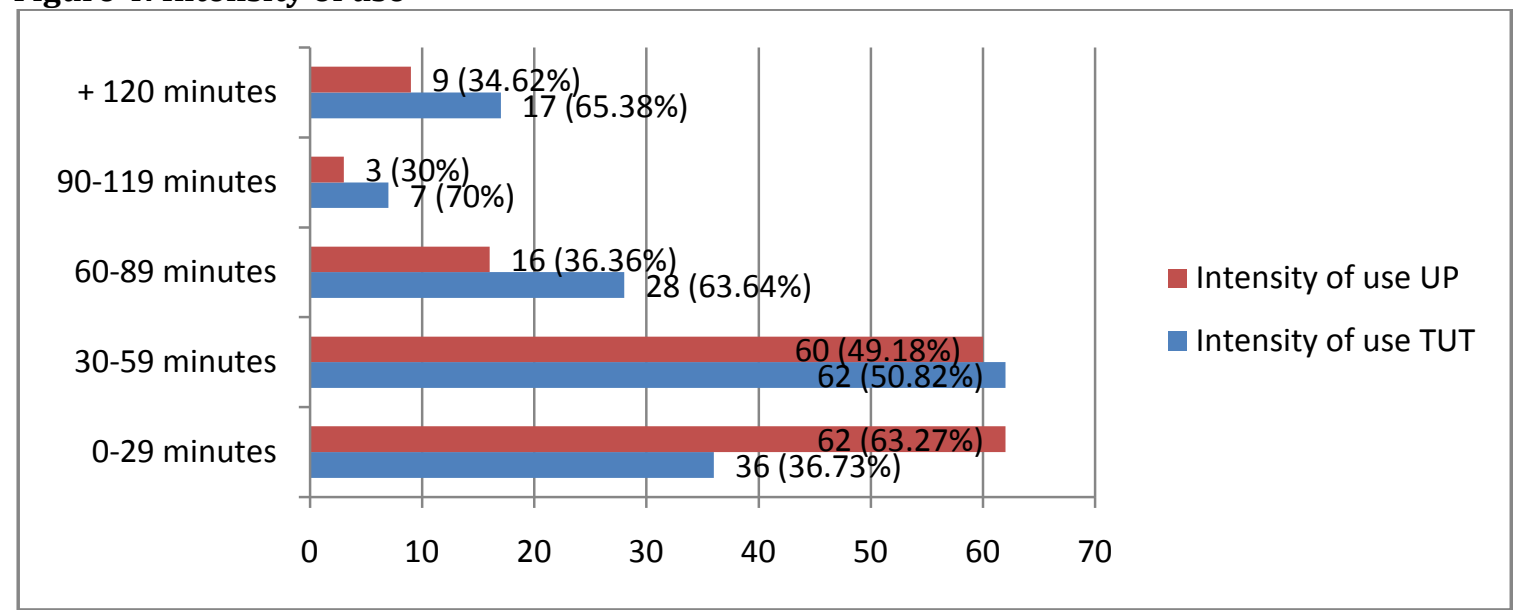

Pearson chi $=14.2650 \operatorname{Pr}=0.006$

Table 1: Purpose of use

\begin{tabular}{|c|c|c|c|c|c|c|}
\hline \multirow[t]{2}{*}{ Students' reasons for using the Internet } & \multicolumn{2}{|l|}{ TUT } & \multicolumn{2}{|l|}{ UP } & \multirow{2}{*}{$\begin{array}{l}\text { Chi- } \\
\text { square }\end{array}$} & \multirow[t]{2}{*}{ P-Values } \\
\hline & Freq. & $\%$ & Freq. & $\%$ & & \\
\hline To play video games & 7 & 4.83 & 15 & 10.14 & 2.971 & 0.848 \\
\hline For work-related tasks (part-time students) & 25 & 17.24 & 40 & 27.03 & 4.063 & 0.438 \\
\hline Because it is fun & 28 & 19.31 & 47 & 31.76 & 5.958 & 0.147 \\
\hline To get news updates & 40 & 27.59 & 39 & 26.35 & 0.057 & 1.000 \\
\hline To download files & 33 & 22.76 & 58 & 39.19 & 9.234 & 0.024 \\
\hline For enhancing my personal knowledge & 63 & 43.45 & 71 & 47.97 & 0.604 & 1.000 \\
\hline To socialise & 60 & 41.38 & 95 & 64.19 & 15.294 & 0.001 \\
\hline To keep in touch with family and friends & 72 & 49.66 & 85 & 57.83 & 1.781 & 1.000 \\
\hline For personal tasks & 68 & 46.90 & 104 & 70.27 & 16.506 & 0.000 \\
\hline For academic purpose & 87 & 60 & 94 & 63.51 & 0.383 & 1.000 \\
\hline
\end{tabular}

* Pearson chi2 (1) / Bonferroni adjusted p-values

Valid cases: 293, Missing cases: 7

Overall Test(s) of Significance: Pearson chi2 (107) $=138.0568 \operatorname{Pr}=0.023$ 
The Stata 11's mrtab command was used to perform multiple response analysis. The interpretation is performed at 95\% confidence limit. In order to assess whether the observed differences between the institutions are significant or not, an overall Pearson or likelihood-ratio $\chi 2$ test which is based on an expanded table of the frequencies of response "patterns" by institutions was performed. The institutions are significantly different in the usage of internet usage $(\mathrm{p}=0.023)$. In particular, they differed in how the use internet to download files $(\mathrm{P}=0.024)$, personal tasks $(\mathrm{P}=0.000)$, and to socialize $(\mathrm{P}=0.001)$.

\section{Conclusion and Recommendations}

The analysis of Internet access shows how infrastructures alone have no effect on students' academic performance (Neuman \& Celano, 2006; Warschauer, 2008), while the place where Internet is used should rather be taken into account. Amongst the university students of the Tshwane region, the Internet is mostly used on campus $(52.21 \%)$, then at home (37.79\%): The TUT students mostly use it on campus (62\%) while the UP students mostly use it at home (48.32\%). The students' believe that they have a moderate level of computer literacy (62\%). However the underlying differences that exist in this regard appear to be more favourable to TUT (54.30\%) than to UP (45.70\%). Since the model used for the current study defines digital literacy as the different skills for using the Internet, the above result could suggest that the students of TUT appear to be more sophisticated in their usage compared to the UP students or that other differences could be attributed to other reasons. Overall, the university students in the Tshwane region use the Internet between 30 to 59 minutes. Amongst the students in the sample who use the Internet within that time frame, 62 $(50.82 \%)$ are TUT students and $60(49.18 \%)$ are UP students. Another usage time of Interest is 0 to 30 minutes, where $62(63.27 \%)$ users are UP students and $36(36.73 \%)$ are TUT students. The students Internet usage patterns also differ on the reasons for using the Internet $(\mathrm{P}=0.023)$. Only three main reasons were deemed significant (to download files, for personal tasks and to socialise) and most responses came from the UP students. In summary, the university students in the Tshwane region differ in their Internet usage as it was expected, particularly amongst the UP and TUT students. The results concur with that of previous studies conducted overseas (Van Dijk \& Hacker, 2000; Hargittai, 2002; Di Maggio et al, 2004; Van Dijk, 2006; Tella, 2007), were the four factor on which this model is based revealed digital inequality amongst students from two different institutions/settings. Such differences could be imputed to possible differences in ICT (Information and Communication Technology) infrastructures, the university's respective syllabi, (or teaching method), the cultural differences amongst the students from each institution. Otherwise, such differences may be indicative of the limitation to the methodology used for this study. Finally, the fact that the university students in the Tshwane region can be profiled on the basis of the results obtained over and above specific situational and personal characteristics, provides important opportunities for marketers for better understanding the needs and expectations of the university students; and by extension, to those of the youth market, since the sample elements belonged to the 18 to 34 years old age group. A proper segmentation would present an important mean by which marketers can keep in touch with their consumers' expectations.

Limitation of the Study: This research was of a descriptive character and of limited scope; hence the results reported are limited in sample generalisability and situation generalisability. For instance, the samples were limited to two selected institutions (TUT and UP) solely in the Tshwane region. Second, the usual caveats applied to the use of "intercept" technique must be acknowledged (e.g. respondent's time pressures). Third, the differences between the two institutions in terms of ICT services as well as in their student profiles meant that combining the data may have left out important student differences which affect usage patterns and perceptions. Fourth, this study was in part reliant upon the assumption that findings of overseas Internet usage studies could be generalisable to South Africa and vice-versa. Despite these limitations, the findings of the study did provide a platform for future investigations and diagnosis as well as yielded valuable insights into a number of pertinent variables. Clearly, additional factors would be worth specifying and sample size could be increased. A priority for future research should be to examine the degree of fit between the demographic and psychographic profiles of university students and the perceived attributes of Internet (using an adoption of innovation model) for different institutions, or investigating the relationship between Internet usage and academic performance. 


\section{References}

Di Maggio, P., Hargittai, E., Celeste, C. \& Shafer, S. (2004). From unequal access to differentiated use: a literature review and agenda for research on digital inequality [report online]. http://www.eszter.com/research/pubs/dimaggioetal-digitalinequality.pdf

Hargittai, E. (2002). Second level digital divide: differences in people's online skills [article online]. First Monday, 7 (4) http://firstmonday.org/issues/issue7_4/hargittai

Idowu, A. P., Idowu, A. O. \& Adagunodo, E. (2004). A comparative study of information and communication technologies at higher educational institutions in Africa: case studies from Nigeria and Mozambique. Journal of Information Technology Impact, 4(2), 67-74.

Li, N. \& Kirkup, G. (2005). Gender and cultural differences in Internet use: a case study of China and the UK. Computers and education, 48, 301-317.

Neuman, S. \& Celano, D. (2006). The knowledge gap: implications of leveling the playing field for low-income and middle-income children. Reading Research Quarterly, 41(2), 176-201.

Rosenburg, N. (2001). Challenges to the Social Sciences in the new millennium, in Social Sciences and Innovation, Paris, OECD.

Tella, A. (2007). University of Botswana undergraduates' uses of Internet: implications on academic performance. Journal of Educational Media \& Library Sciences. 45(2), 161-185.

Van Dijk, J. (2006). Digital divide research, achievements and shortcoming. Poetics, 34(4-5), 221- 235.

Van Dijk, J. \& Hacker, K. (2000). The digital divide as a complex and dynamic phenomenon. In: 50th Annual Conference of the International Communication Association (1-5 June 2000: Acapulco) [communication <http://www.gw.utwente.nl/vandijk/research/digital_divide/Digital_Divide_overigen/ pdf_digitaldivide_website.pdf>

Warschauer, M. (2008). Laptops and literacy: a multisite case study. Pedagogies: An International Journal, $3(1), 52-67$. 